Elsevier required licence: (C2018. This manuscript version is made available under the CC-BY-NC-ND 4.0 license http://creativecommons.org/licenses/by-nc-nd/4.0/ 
$\underline{\text { Title }}$

Opportunities for adaptive online collaboration to enhance rural land management

$\underline{\text { Author names and affiliations }}$

Alex Baumber ${ }^{1}$

Graciela Metternicht ${ }^{2}$

Peter $\mathrm{Ampt}^{3}$

Rebecca Cross ${ }^{3}$

Emily Berry ${ }^{2}$

${ }^{1}$ Faculty of Transdisciplinary Innovation, University of Technology Sydney, Australia

${ }^{2}$ School of Biological, Earth and Environmental Sciences, Palaeontology, Geobiology

\& Earth Archives Research Centre (PANGEA), UNSW Sydney, Australia

${ }^{3}$ Sydney Institute of Agriculture, School of Life and Environmental Sciences, University of Sydney, Australia

Corresponding author

Alex Baumber email: alex.baumber@uts.edu.au 


\title{
Opportunities for adaptive online collaboration to enhance rural land management
}

\begin{abstract}
Cross-property cooperation has the potential to enhance the effectiveness of environmental management actions that cut across property boundaries. Online tools can facilitate this and overcome barriers to landholder engagement in collaborative management. However, collaborative online tools need to be designed and tailored to users' needs and values, and landholder participation in the development process is critical to ensuring uptake and long-term use.
\end{abstract}

This article presents a case study from the Central Tablelands region of New South Wales, Australia, where landholders have been involved in participatory development of a new online collaboration tool. The case study results highlight the significance of issues such as internet access, privacy, technical proficiency and differing stakeholder objectives. A landholder survey identified mapping and the uploading of monitoring data as important functions for the online tool, but these were not rated as highly as functions relating to data security, sharing settings and key term searches. Consequently, we recommend that a future online collaboration tool for the region is not framed specifically as a mapping or citizen science tool, but rather as an adaptive collaboration and communication tool that can incorporate a variety of data types and formats and be modified over time in line with changing landholder needs.

\section{Keywords}

collaboration; monitoring; adaptive co-management; online tool; landscape-scale; mapping 


\section{Introduction}

Cross-property cooperation can enhance the effectiveness of environmental management actions that cross property boundaries, including for monitoring (Lawrence et al., 2007), sustaining ecosystem services (Rickenbach et al., 2011) and developing new commercial enterprises (Baumber et al., 2009). However, a tension often exists between the scale at which such collaboration may be required and the scale at which landholders make land management decisions (Wyborn and Bixler, 2013). Online tools have the potential to bridge this gap by enhancing communication, datasharing and collaborative decision-making (Palomino et al., 2017). In this article, we employ a case study approach to assess interest in online collaboration tools for land and natural resource management in the Central Tablelands region of New South Wales (NSW), Australia.

In Australia, the Landcare movement has been a prominent example of collaborative cross-property land management since the mid-1980s, with local groups engaging in tree planting, erosion control, pest and weed management, riparian zone fencing and other activities for both conservation and production (Compton and Beeton, 2012; Curtis et al., 2014; Lockwood, 2000). However, Landcare activities have been declining in some areas due to changes in government support and demographic shifts, including the migration of rural amenity "lifestylers" into many areas (Tennent and Lockie, 2013). These changing demographics can create challenges for landholders in engaging with neighbours through traditional networks and communication strategies (Meadows et al., 2014).

Online collaboration tools offer new platforms for landholders to store and share monitoring data (Newman et al., 2010), to enhance the speed and scope of engagement 
with other stakeholders (Rotman et al., 2012) and to participate in planning around landscape-scale issues (Meyer et al., 2016). Furthermore, online tools that allow land managers to collectively record data, plan management trials and modify practices in response to new information may enhance their adaptive capacity in line with the notion of "adaptive co-management" (Berkes, 2007). As such, online tools have the potential to enhance not only the level of collaboration amongst landholders, but also to enhance their capacity to adapt land management to changing circumstances.

Section 2 of this article provides a global-scale review of online tools for collaborative environmental management. The case study region is then introduced in Section 3, along with the methods and results of a landholder survey. Section 4 provides a discussion of the implications of the case study research for the broader field of online collaboration tools.

\section{Online tools for collaborative environmental management - a global overview}

Rural landholders may choose to utilise online collaboration tools for a wide range of purposes, including farm management, planning conservation projects, developing new enterprises and sharing data through citizen science programs. Palomino et al. (2017) argue that advances in geospatial data and tools can facilitate greater collaboration in four main ways: (1) enabling groups to divide up tasks across expansive geographic scales; (2) allowing greater sharing of data and peer review; (3) enhancing communication between stakeholders; and (4) allowing integration of complementary tools, such as mapping and communication tools.

The features of online collaboration tools vary according to their purpose and the characteristics of their users. For example, citizen science websites and apps generally do not require users to have a high level of technical skill and employ a modular system 
whereby each user completes a small part of the project. In contrast, participatory geographic information systems (PGIS) may require a skilled facilitator to assist users (e.g. Karimi and Brown, 2017; Meyer et al., 2016). Tools that are primarily focused around mapping and designed to allow users with little or no training to create their own maps may be classed as "neogeography" (Turner, 2006). While mapping is a central feature of neogeography and PGIS, other tools may focus more on facilitating communication or sharing non-spatial data such as photographs and case studies.

\subsection{Participatory Geographic Information Systems (PGIS)}

Participatory GIS (PGIS), including related terms such as Public Participation GIS (PPGIS) and participatory mapping, have been used for a range of applications in Australia and many other countries. Karimi and Brown (2017) note that PGIS approaches often differ between developing countries, where PGIS is used to mediate disputes over access to land and natural resources, and developed countries, where PGIS is used to understand competing values and preferences around how land should be used.

Meyer et al. (2016) report the results of two regional case studies in South Australia, where regional planners developed a web-based landscape futures PGIS tool. Government agency staff, community advisory board members and farmers were engaged in the setting of landscape goals and evaluating the outputs of the tool, while project team members with specific expertise undertook the data collation, designed the interface and conducted social research into the tool's effectiveness. Karimi and Brown (2017) report on a similar exercise in Queensland, where government agency staff assigned values to different land uses such as conservation, mining, residential development and tourism. Common features of these two examples are that they were 
targeted at a regional scale $\left(4000-80,000 \mathrm{~km}^{2}\right)$, focused primarily on government agency staff and required expert facilitators.

Jankowski (2009) discusses the potential of PGIS to enable groups of local people to participate in decisions shaping their communities, shown through two case studies on the management of water resources in Idaho. As with the case studies of Meyer et al. (2016), Jankowski’s case studies involved GIS resources developed by agency staff and experts, with the role of landholders being to identify values, goals and strategies to address regional challenges. Ramsey (2009) argues that a limitation of some PGIS approaches is that they frame the exercise as one of "problem-solving" and present GIS data in a manner that can pre-determine how users should view the problem and which solutions may be appropriate.

\subsection{Citizen science, volunteered geographic information and neogeography}

Citizen science, or crowd science, seeks to engage volunteers in the collection, analysis and curation of scientific data, with such volunteers typically lacking formal credentials or professional positions in scientific institutions (Rotman et al. 2012). Citizen science projects can be divided into three categories (Bonney et al., 2009): Contributory projects, where scientists design the project and volunteers contribute data; Collaborative projects, where volunteers have input into project design; and Co-created projects, where scientists and volunteers are involved in all parts of the project.

Landholders may be a target group for participation in citizen science projects through the collection and reporting of data on environmental issues in their area (Newman et al., 2010). FeralScan is an Australian example developed by the Centre for Invasive Species Solutions. Branded as "citizen surveillance", it allows landholders and other community members to record and share sightings of invasive species, including foxes, 
pigs, goats and cats (FeralScan, 2017). In other cases, volunteers are involved in data analysis rather than collection, such as the site www.globalfishingwatch.org, which involves analysis of large datasets on marine vessel movements to monitor compliance and identify illegal activity (Robards et al., 2016).

The internet has provided the opportunity for citizen science to become more widely distributed and practiced (Rotman et al., 2012). The integration of online mapping and citizen science can enhance the ability of landholders to incorporate results into their land management practices (Newman et al., 2017). However, care is required to ensure that participant tasks are suited to their differing skill levels (Franzoni and Sauermann, 2014).

Where citizen science involves the uploading of data via online tools, it overlaps with VGI, or Volunteered Geographic Information (Goodchild, 2007). However, citizen science does not necessarily require an online component and the contribution of VGI is not necessarily motivated by scientific goals (e.g. users uploading photos or marking points of interest). Similarly, citizen science and VGI can overlap with neogeography, defined by Turner (2006, p. 3) as "people using and creating their own maps, on their own terms and by combining elements of an existing toolset". While the philosophy of users defining their own goals and uses for maps makes neogeography a broader concept than citizen science, the extent to which many users are truly able to engage "on their own terms" has been challenged due to issues such as access and education (Haklay, 2013).

\subsection{Incorporation of property and landscape data into participatory online tools}

Land managers can use participatory online tools in several ways to maximise their relevance for decision-making at the property or landscape scale. One option is to 
engage landholders in "ground-truthing" GIS-derived data. For example, Al-Wadaey and Ziadat (2014) asked local farmers in Syria to validate GIS-generated maps on land vulnerability to soil erosion. The maps were modified according to the farmers' responses, and subsequently used to distribute land management funding to landholders.

The design of citizen science tools can increase their relevance for property-scale decision-making by feeding data back to landholders in user-friendly formats. One such example is the Atlas of Living Australia, an online mapping tool that allows community members to upload data according to citizen science principles and to display sightings of threatened species or downloading them for use in GIS projects (The Atlas of Living Australia, 2017).

In cases where neighbouring landholders are prepared to work together and share sensitive data, it may be feasible for property-level monitoring data to be shared via online tools. For example, Ampt and Baumber (2010) report on a system of reference sites to be monitored using Landscape Function Analysis (LFA) and shared via an online tool amongst landholders in far-western NSW. Rapid assessment tools such as LFA may be well-suited to the compilation and sharing of cross-property data in this fashion, as they can encourage communication and learning while not requiring all participants to have the time and motivation required for full sustainability assessments (Marchand et al., 2014).

\subsection{Barriers and opportunities relating to the use of online tools by landholders}

While the increasing use of online collaboration tools for natural resource management presents opportunities to share knowledge and adjust land management, there are also a range of barriers to the use of these tools by landholders. Participatory online tools can help to overcome geographical barriers (Rotman et al., 2012) and to democratise the 
process of producing and using geographical information (Byrne and Pickard, 2016). However, unequal internet access, a lack of technological proficiency, variable data quality, differing motivations and the need for trust and transparency can all pose barriers, particularly in rural and remote settings where most land is managed.

Lack of broadband internet access, can pose a barrier to the use of online collaboration tools in remote areas, developing countries and among poor and marginalised people (Haklay, 2013). A lack of digital literacy among many of the same demographic groups can compound access challenges (Cinnamon and Schuurman, 2013).

Even in developed countries with high overall levels of internet usage, such as the United States or Australia, the unintentional exclusion of certain groups from participatory mapping or planning projects that rely on online tools may lead to the under-representation of certain opinions and values. For example, in their study of indigenous relationships with land on the Flathead Indian Reservation in Montana, Carver et al. (2009) found that the older members of the community with the most valuable historical knowledge were the least technologically literate. Mekonnen \& Gorsevski (2015) identify some ways to overcome these barriers, such as the use of appropriate language and user-friendly features.

Advances in mobile technologies and the simplification of user interfaces have the potential to break down access barriers and further democratize the use of online collaboration tools (Cinnamon and Schuurman, 2013). Writing in 2007, Goodchild lamented that "In principle, much could be achieved through mobile phones, which often have the ability to connect to the Internet and to capture images, but the tools needed to exploit this limited environment as a source for VGI do not yet exist" (Goodchild, 2007 p. 220). A decade on, Palomino et al. reported "a rapid expansion in 
the sources of geospatial data from mobile devices" (Palomino et al., 2017 p. 80), with several mapping tools operating on mobile platforms. Furthermore, they highlighted that technological literacy has become less of a barrier for citizen science projects, due to the "availability of low-to-no cost, easy-to-launch tools that require little infrastructure investment or technical knowledge by users" (p. 88).

Maintaining data quality can be a barrier for online tools, particularly citizen science projects where data quality needs to be considered in the recruitment of data collectors, collection methods, data entry and analysis (Newman et al., 2010). In public participation GIS, data quality is linked with sampling design, participation rates and inclusion of relevant actors (Brown and Kytta, 2014). Sufficiency of spatial data is a parameter affecting its quality for meaningful analysis. One option to increase transparency is to provide users of the data with an indication of its quality and reliability. For example, the Atlas of Living Australia allows users to display biodiversity data based on "spatially-valid records", "spatially-suspect records" or "expert distribution areas" (The Atlas of Living Australia, 2017). The latter aligns with the concept of social approach to data quality proposed by Goodchild and Li (2012).

Aligning the motivation of users with project objectives is a common challenge, particularly for citizen science projects. Rotman et al. (2012) highlight that motivations are highly variable, with some users interested in projects that would benefit their local area, and others motivated by rewards. Franzoni and Sauermann (2014) discuss the need for tailored strategies to encourage participants at all engagement levels, including the numerous less-frequent contributors who may contribute the largest proportion of data over time. Tools that require less time and effort may increase participation of timepoor or less-motivated users (Marchand et al., 2014). 
Trust and transparency are critical considerations for tools that rely on public participation. In contexts where GIS tools are not widely available or resulting analyses are not shared with contributors, community members may view GIS tools as elitist and indicative of a top-down approach to land management (Carver et al., 2001). Wang et al. (2008) commented that, in their Chinese case study, locals were suspicious of final outcomes as they assumed that the views of officials would hold more influence than their own views.

Haklay (2013) argues that true democratisation of PGIS, VGI and neogeography first requires a recognition that technology platforms and mapping tools are most often designed by a small demographic that is male, highly-educated and affluent. Cravens $(2014 ; 2016)$ emphasises the need for software producers to work closely with targeted users when developing tools, including piloting and adaptation to identify and remedy unexpected challenges arising from the design of the interface. Genuinely participatory and inclusive approaches require broad-based community involvement, not only in the collection of data, but also in the design of the technology platforms and mapping projects.

\section{Case study - NSW Central Tablelands}

\subsection{Aims and introduction}

In this case study research, we aimed to assess the interest of landholders in the New South Wales Central Tablelands in using online tools to collaborate on natural resource management, including the features they would value most in a hypothetical online tool. The study was funded by the NSW Environmental Trust and involved three universities (The University of Sydney, The University of New South Wales and The University of 
Technology Sydney), Landcare NSW Inc. and the Central Tablelands Local Land Services (a NSW Government agency).

The Central Tablelands region is located in central NSW across the plateau formed by the Great Dividing Range, which divides the coastal strip of eastern Australia from its western slopes and plains. Major cities and towns include Bathurst, Orange and Mudgee (Figure 1). The case study focuses on two locations in the region, referred to as the NE and SW case study areas.

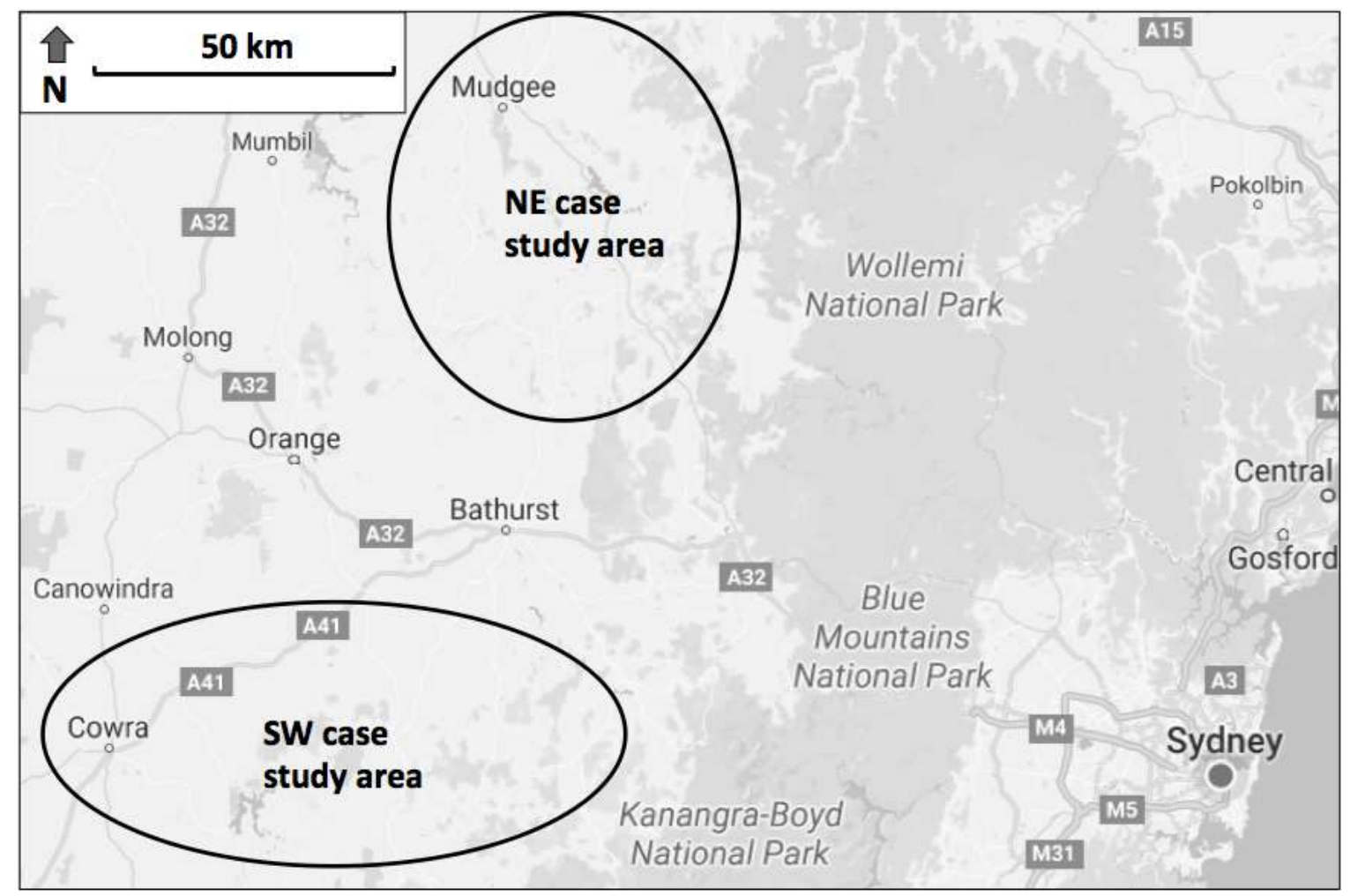

Figure 1: Location of the North-East (NE) and South-West (SW) case study areas in the NSW Central Tablelands. Map data: Google.

The dominant land use across the Central Tablelands is sheep and cattle grazing (NSW Government, 2007), with significant conservation areas in the east and cropping in the west. Mean annual rainfall (Bureau of Meteorology, 2012) is highest in the east (around 
$900 \mathrm{~mm}$ at Lithgow), declining towards the north (670 $\mathrm{mm}$ at Mudgee) and west (640 $\mathrm{mm}$ at Bathurst).

The Central Tablelands region has shown strong evidence of what Holmes (2006) terms the "multifunctional rural transition", with an influx of so-called "rural lifestylers" who are not dependent on the land for their income (Central West Independent Review Panel, 2007). Rural lifestylers concentrate mostly around major towns and transport routes to Sydney, which is a two to four hour drive from most parts of the region.

Environmental issues in the Central Tablelands vary depending on the extent of remnant native vegetation, rainfall, elevation and soil type. The dominance of coarse-grained acidic rock types has led to sandy-textured soils that are susceptible to erosion, while parts of the region are also susceptible to soil salinity (Central West Catchment Management Authority, 2007). Runoff from the tablelands supplies a number of reservoirs that supply potable water to Sydney as well as irrigation water for inland farming communities.

The Landcare movement is active in the Central Tablelands, including many small local groups as well as larger umbrella groups such as Watershed Landcare, covering 9000 $\mathrm{km}^{2}$ around Mudgee. For the region, researchers have previously identified opportunities for cross-property collaboration on a range of activities that combine conservation and production, including grazing management to improve landscape health (Ampt and Doornbos, 2011) and agroforestry for erosion control and biodiversity (Baumber et al., 2012). 


\subsection{Online collaboration tools with relevance to the case study region}

A number of online collaboration tools operate in the case study area, with landholders asked about their usage of such tools as part of the case study (see methods section 3.3). The New South Wales Landcare Gateway (landcare.nsw.gov.au) enables landholders to find information about active environmental groups in their area and allows group coordinators to post information such as a basic map, news, images, case studies, contact details and links to social media. However, this platform was not initially designed for regular Landcare group members to upload or manipulate data. NSW Spatial Information Exchange (maps.six.nsw.gov.au) has more of a focus on spatial data, particularly cadastral data relating to property boundaries and survey markers, allowing users to display or download, but not upload, data. The NRM Hub (www.nrmhub.com.au) has more of a production focus, allowing landholders to build customised maps and analyse the condition of their properties over time to better understand their long-term carrying capacity and pasture utilisation. However, it does not focus on cross-property activity or provide a platform for farmer-to-farmer communication.

Two previously-mentioned online platforms for citizen science that operate in the case study region are the Atlas of Living Australia (www.ala.org.au) and FeralScan (www.feralscan.org.au). The Atlas of Living Australia (ALA) has a focus on native species, particularly threatened species, while FeralScan focuses on introduced pest animals. ALA allows users to upload data and view data uploaded by others, as well as to download maps and data layers. As well, the NSW Bionet: Atlas of NSW Wildlife (www.bionet.nsw.gov.au) is a NSW Government resource designed primarily to allow individuals to search government databases for listed plants and animals. While species 
sightings can be displayed on a map, users can only contribute sightings by completing and submitting a spreadsheet.

A number of online tools designed to connect food consumers, producers, gardeners and landholders include coverage of the NSW Central Tablelands. The Open Food Network (openfoodnetwork.org) seeks to link urban consumers to rural food producers and retailers stocking their produce. The mapping system allows rural landholders to upload information about their production systems, including how to purchase their produce. Other online mapping tools are primarily aimed at connecting urban users with community gardens or underutilised land, such as the Australian City Farms and Community Gardens Network (directory.communitygarden.org.au) and 3000 Acres (3000acres.org), which is based on the 596 Acres project in New York City (596acres.org).

As well as the regional platforms listed above, landholders in the Central Tablelands can share information via global social media platforms such as Facebook, Twitter and Instagram, along with online GIS tools such as Google Earth, ArcGIS Online, QGIS Cloud and NextGIS. These tools allow landholders to upload, download and manipulate data to build their own geospatial projects based on topics of interest to them, rather than being confined by the priorities of the developers of other sites. They also commonly offer the advantage of being free and/or open source, with increasing interoperability and ongoing development of new functionality by their user communities (Palomino et al., 2017). However, for neighbouring landholders to collaborate through these platforms, they first need to set up their own administrative and communication structures, which can exist along a spectrum from informal (neighbours sharing data without any agreements in place) to formal (e.g. Landcare group or other incorporated association). As such, there are advantages and disadvantages in using either existing 
platforms focused on specific activities or developing customised projects through free and/or open-source online GIS tools.

\subsection{Case study methods}

We used Participatory Rural Appraisal (PRA) to collect data and analyse results (Campbell, 2001; Narayanasamy, 2009). This approach treats rural people as coproducers of knowledge and seeks to enable them to share, enhance and analyse their knowledge for use in participatory planning and action (Chambers, 1994). In September and October 2016, two Participatory Rural Appraisal (PRA) exercises were undertaken in the NE and SW case study areas, with 26 and 29 landholders interviewed in the two areas respectively. Landholders were recruited by drawing on the networks of key stakeholders involved with organisations such as the Watershed Landcare Group, which covers most of the NE case study area, and Hovells Creek Landcare Group (SW area) and the Kanangra-Boyd to Wyangala (K2W) regional partnership, which covers most of the SW case study area and has a focus on native vegetation connectivity. Staff from the Central Tablelands Local Land Services, a NSW Government agency, were involved in recruitment and interviewing in both case study areas.

Each PRA involved a team of interviewers working in pairs, with one university researcher partnered with a local stakeholder from either a Landcare group, the K2W group or the Central Tablelands Local Land Services. Interviewers asked each landholder a range of questions in a semi-structured interview format covering land management practices, history of collaboration around conservation and production and interest in further collaboration under different models (e.g. informal, co-operatives, incorporated associations, business ventures). The final interview questions asked 
interviewees whether they currently used any online tools to collaborate and whether they would be interested in using a new or revised online collaboration tool.

At the end of each interview, interviewees were asked to complete a written survey covering the following topics:

1. Internet access and usage: Sub-questions covering hours per week spent on the web, time willing to spend using an online collaboration tool, quality of internet access and devices used to access the internet (PC, laptop, phone, tablet).

2. Functions most valued in a potential new online collaboration tool: Rating options from a list including mapping, search function, discussion forum, links to social media, ability to upload monitoring data, different member categories (e.g. Landcare group, government, commercial service provider), ability to buy and sell products or services, differentiated access levels (e.g. private, group and public visibility options) and data security.

3. Most important characteristics of a "user-friendly" online tool: interviewees had to select from a list including compatible with phone/tablet, fast loading speed, large clear text, simple colour scheme, simple menu options, accessible to vision or hearingimpaired people, other (more than one option could be chosen).

4. Types of data they would be willing to share with other landholders online: landholders had to choose from a list including monitoring results, photos, case studies, contact details, reviews/ratings of services or products they have used, other (more than one option could be selected).

5. Willingness to pay a fee to access an online tool that provides economic and conservation benefits: Options were zero (must be free), up to AUD10 per year, 
AUD11-20 per year, AUD21-50 per year and more than AUD50 per year.

The interview questions and survey are included in the Supplementary Material.

To illustrate some of the potential functionality of an online collaboration tool, screenshots of existing tools were shown to interviewees prior to completing the survey. The NSW Landcare Gateway (landcare.nsw.gov.au/map) was used to demonstrate the ability to link data to a point on a map. The project's Facebook page (www.facebook.com/landholdercollab) was used to demonstrate linking an online tool to social media. The UK Community Maps site (communitymaps.org.uk/project/airquality-monitoring) was used to demonstrate the ability to upload and view monitoring data. Lastly, the Forage Fish map on the Canadian Community Mapping Network (cmnmaps.ca/FORAGEFISH2/map_public.php) served to demonstrate the ability to include private group spaces that limit sensitive data to group members with a login. An advantage of conducting both a written survey and a semi-structured interview was that it enabled responses to be recorded consistently and analysed quantitatively (through the survey), while also allowing for qualitative responses to be captured that expanded on the restricted options provided on the survey from. Many respondents made comments to interviewers while completing the survey and these comments were recorded and transcribed along with their other interview responses.

Overall, 45 of the 55 interviewees completed the survey (22 in the NE case study area and 23 in the SW case study area). There was a mix of large commercial farmers and smaller non-commercial landholders in each area. Ten interviewees declined to complete the survey (four in the NE case study area and six in the SW case study area), with three landholders (all in SW) explicitly citing a lack of current internet usage and disinterest in using an online tool as reasons for not completing the survey. Others gave 
no reason, cited a lack of time or offered to complete the survey later, but ultimately did not return it.

\subsection{Results}

\section{Interviewee characteristics}

Participants in the two study regions differed in terms of average property size, property use and the prevalence of rural lifestylers. In the NE area, participants were predominantly small-to-medium landholders ( $n=17 / 26$ interviewees), with more than half identifying as rural lifestylers who had moved to the area from a major city (usually Sydney) and had either "hobby farms" or land managed for conservation. Eight participants were large-scale commercial producers and one was from a government conservation agency. Production was highly diverse in this area, with interviewees producing sheep for wool or meat, beef, wine, alpacas and pigs.

In contrast, participants in the SW study area were predominantly medium-to-large commercial landholders ( $\mathrm{n}=19 / 29$ interviewees) producing sheep (for meat and wool) and beef. Rural lifestylers were less prevalent, with most interviewees coming from inter-generational farming families within the region or nearby. Interviewees informed us that there were a number of absentee landholders clustered in parts of the region.

Interviewees were not asked their age and there was no obvious difference between the two areas in this regard. The potential collaboration issues identified by interviewees were similar in each area, including weeds and pest animals, ecological restoration, production practices and tourism. 


\section{Internet usage and preferences}

Internet usage and access was variable, with 6-10 hours/week being the most commonly-selected category for internet usage in both areas (Figure 2). The SW area featured more landholders reporting very low internet usage levels. The most commonly-used online collaboration tools reported by interviewees were Facebook, farming discussion forums and the NSW Landcare Gateway, while many tools such as the The Open Food Network, NRMHub, The Atlas of Living Australia, NSW Bionet, FeralScan, Google Earth and QGIS Cloud were not mentioned at all.

When asked how much they would use an online tool for connecting with other landholders, the average amount of time nominated was around 2 hours per week (2.1 for NE and 1.8 for SW). For these two questions only, the three SW landholders who declined to complete the survey were included in the results (under the lowest category for current usage and zero usage for a new tool).

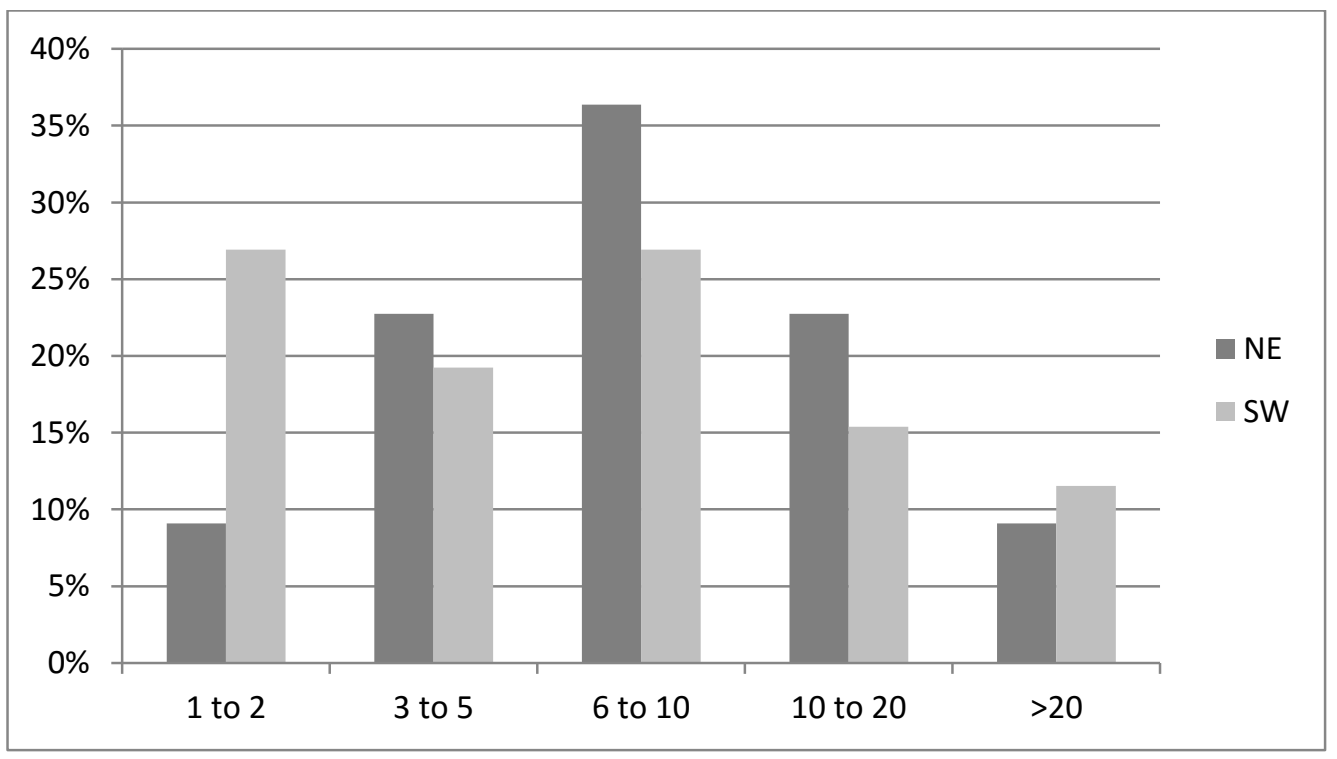

Figure 2: Hours per week spent on the web in each case study group. 
The devices used to access the internet differed between the two case study areas, with PC and laptop more common in the SW and phone and tablet more common in the NE (Figure 3).

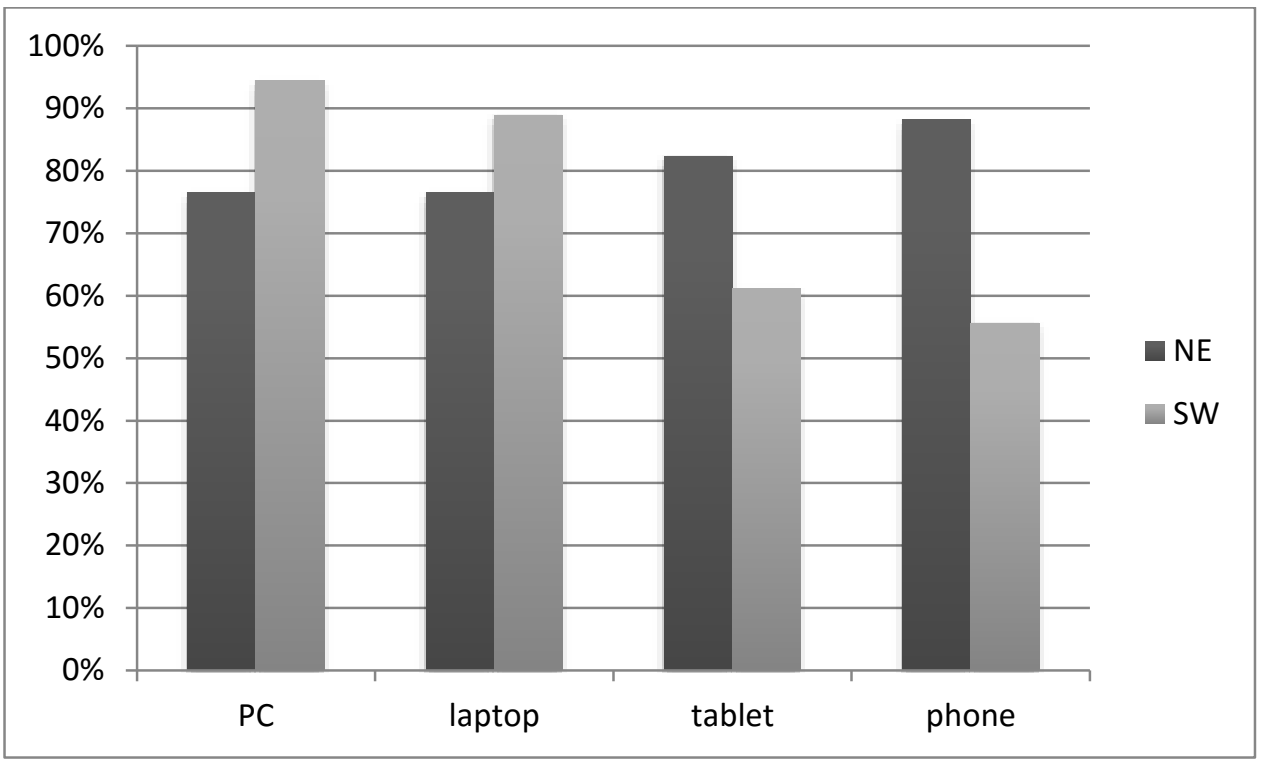

Figure 3: Devices used to access internet in each case study area. Respondents could choose more than one option.

Landholders at both sites reported poor internet access, with interviewee comments including:

"You're talking about fifth generation farmers who don't even have their internet... our internet is a joke. Our phone goes out first drop of rain." (NE19)

"Over the years, you get excited that you get faster internet, and it opens up a whole world of everything. Then you come here and you think, wow. We've got to go back to no mobiles, no landline, and no internet."(NE4)

"Internet access here is absolutely lousy... had we had better internet 
access, we'd probably spend more [time on it]." (SW5)

The percentage of respondents who described their internet access as poor/very poor/terrible or similar was higher in the SW area $(67 \%)$ than in the NE area (53\%). The opposite pattern emerged for those describing internet access as good, reliable or similar (NE 29\%, S W 17\%). The lower level of internet usage and greater reliance on PCs/laptops over mobile devices in the SW area may be linked to poorer reported internet and/or the higher proportion of commercial farmers who had lived in rural areas all their lives.

For the survey question on functionality (Figure 4), results were similar for both sites, with respondents rating data security as most important, followed by ability to choose public or private settings for uploaded data.

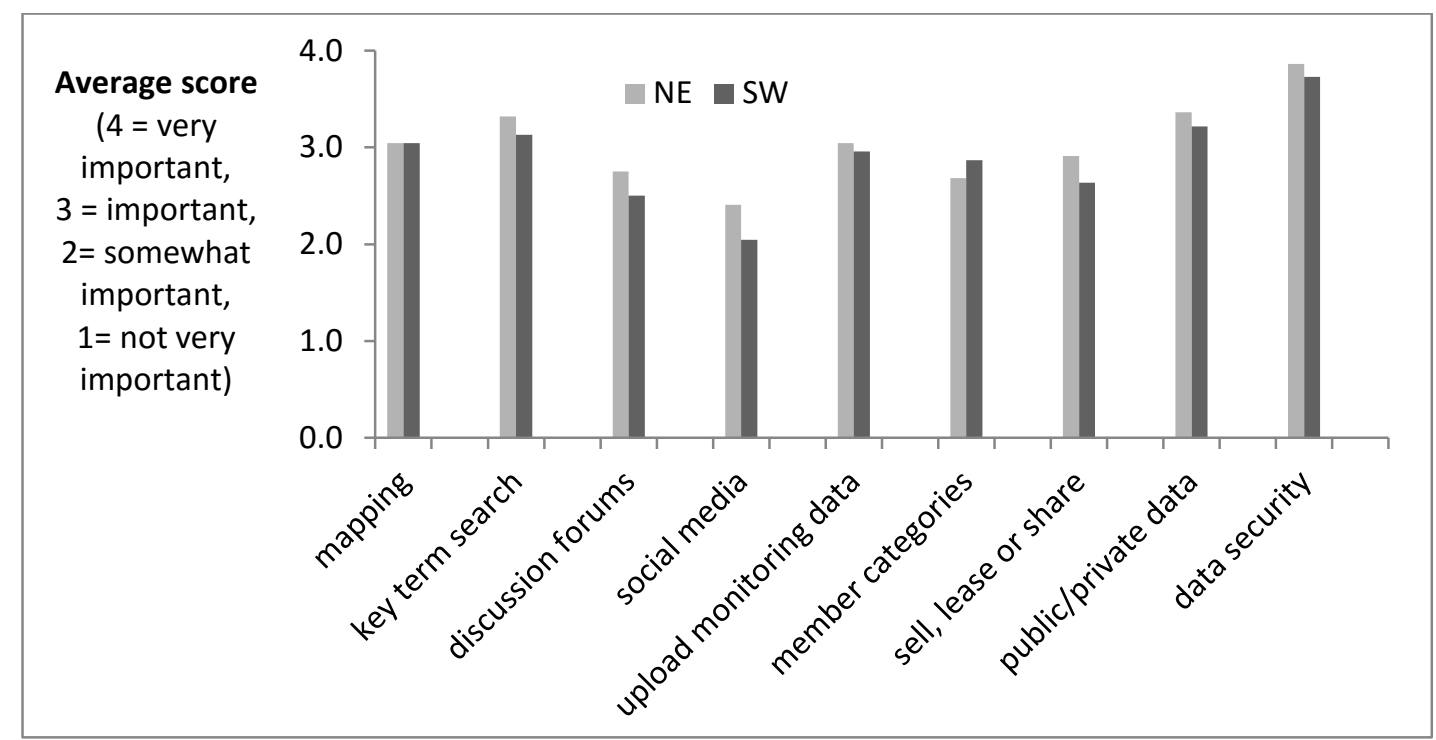

Figure 4: Average ratings for different potential functions of an online tool

The ability to search using key terms (e.g. weeds) was the third-highest ranking function. Mapping and uploading monitoring data are key features for PGIS and citizen science approaches to collaboration, but are only mid-rated functions in Figure 
4. Despite this, a number of respondents made positive comments about collaborative mapping:

"mapping function might be interesting just to see who is interested (NE9)

"let's say the new reveg areas that you're doing... you'd be able to pinpoint them on a map... 'this is what we want to do next year and this is what we've already done'... Look at linkages and try and do infill and things like that to develop a plan..." (SW9)

"it gives you an opportunity to have a look at what is available nearby... You might find people that you don't know, not that far away from you doing something" (NE1)

The ability of a collaborative tool to link to social media was rated lowest of all listed functions, with discussion forums rated second-lowest. One function that was not specifically listed on the survey but came up in interviewee comments was the ability to post upcoming news or events (e.g. pest or weed management):

“even if it's, 'Oh, I'm spraying tussock today'...I think people's time is too valuable to be sitting there calling up your neighbours one by one, you just tell them all at once, just put it out there, 'The helicopter is coming out if you want to get some done as well."” (SW7)

“...information on what's happening. If there's wild dog attacks, things like that. Possible risks to your farm. If there's information about new chemicals to control weeds, or if they're working for you, or if there's particular weeds that are popping up in the nearby area...People could put on there that we're gonna bait. 
And I think, okay, if I've got a problem, I could say, "Yeah, count me in."' (NE20)

When asked which data landholders would be willing to share (from a list provided), monitoring results and photos rated highest at both sites, followed by reviews/ratings, case studies and contact details. However, interviewee comments indicated that willingness to share was highly variable across different data types and other data types left off the survey list may be important. For example:

“...it depends on what it is. Some information I wouldn't mind being out there generally, particularly rainfall data...My carbon storing information, no, no. I don't tell people what I get per kilogram for my meat." (NE5)

Other respondents indicated a willingness to have a wide range of data about land management publically available:

"It's a really non-intrusive way of people checking you out. I say go ahead, stalk us, because that's what I want you to do. Go ahead and have a look at what we do. I've got nothing to hide. What we do is quality work, so if you see something in there that you like and you want us to do something like that for you, then that's fantastic.” (NE3)

When considering the most important features for making an online tool userfriendly (Figure 5), respondents at both sites most commonly selected "simple menu options". This was followed by phone/tablet compatibility and fast loading speed. Some respondents commented that, even with user-friendly interfaces, some landholders may find the technology challenging:

"You got to learn all this though. It is important, but you've still got to be able to 
know what to do. For me, I'm still learning.” (SW 1)

"there's a lot of older people out there too. Our neighbour out there, he can barely do an email. As for going online or doing Facebook or anything like that, it's just not going to happen. You lose access [to] a percentage that could be similar to him out there. How many young people are in farming these days? (NE 6)

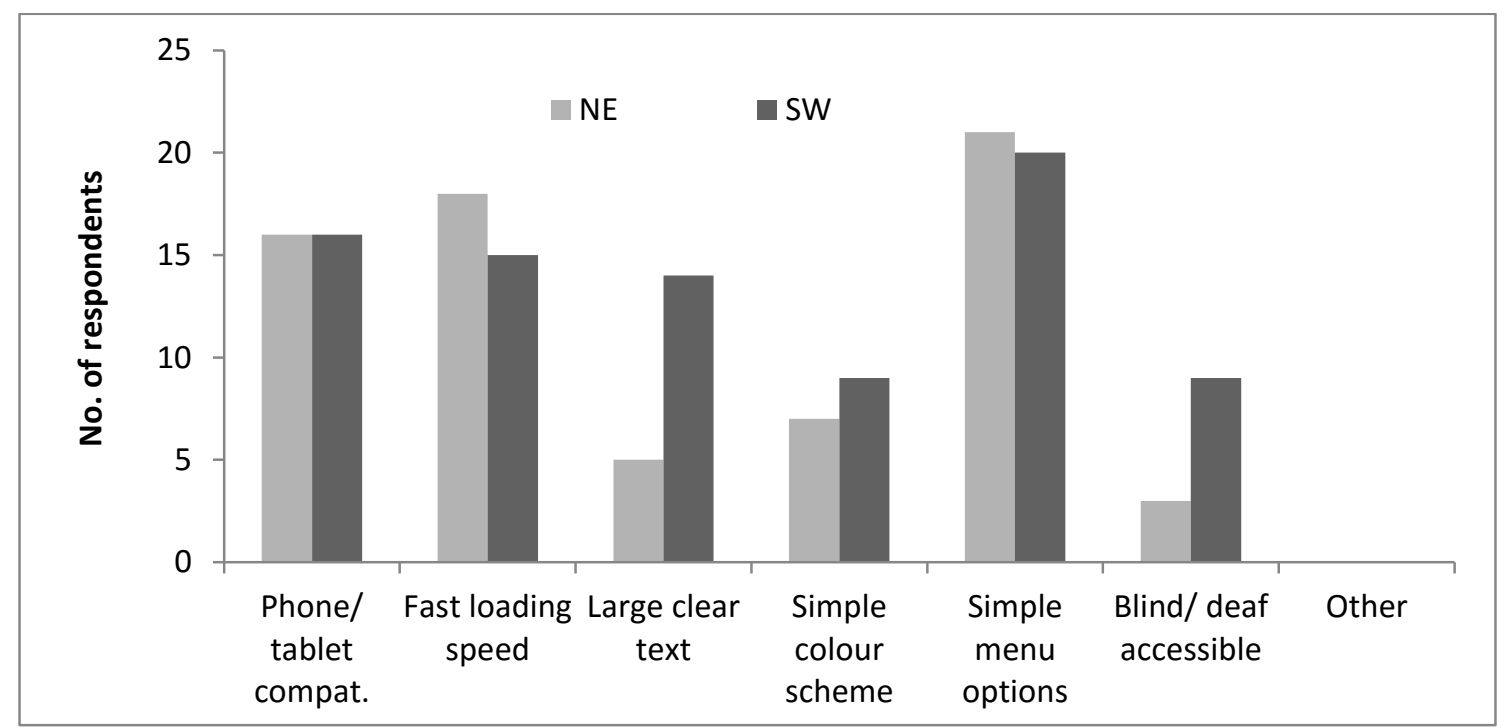

Figure 5: User-friendliness factors selected by respondents in each case study area.

Most respondents were willing to pay for membership, with several noting that value would need to be evident before they would pay. At both sites, the most common fee range nominated was AUD21-50 per year.

Aside from the issues covered in the survey, one theme that came up repeatedly in interviewee comments was the potential of the tool to enhance communication:

"That's a very strong message that's coming through. The need for a better connection with all landholders, essentially. Whereas a traditional area where people have been here for a long time, everyone knew each other... That 
cohesion was there, whereas it's not so much now. Anything that can help bridge those gaps, is gonna be a good thing" (SW23)

"It'd be very interesting to get that communication going because communication just doesn't happen, does it? People that work in silos, "I'm doing my thing on my place... but no one else knows about it." (NE6)

“People aren't gathering anymore, so I think that online discussion forums have to be a really key link to having conversations about what they're doing and what's going to work" (NE14)

\section{Discussion}

The interview responses and results of the online tool survey are relevant to a range of natural resource management stakeholders engaged with landholder in the study area, including: Landcare NSW, which operates the NSW Landcare Gateway; Central Tablelands Local Land Services, which has responsibility for facilitating conservation and sustainable production activities; and the NSW Environmental Trust, which funded the research. As well, these results can inform the development of online tools in other rural and remote locations.

Key implications identified in the case study research relate to mobile device compatibility, poor internet access, users' need for simple menu options, landholders' interest in having differing data sharing settings and the need to ensure that any online tool for the areas is adaptable to multiple potential uses, rather than being framed as a "mapping" or "citizen science" tool. Landholders did not identify many of the existing collaboration tools available in the region as tools they use regularly. In addition, many of these tools are promoted as either mapping tools (e.g. Google Earth, QGIS Cloud) or 
citizen science tools (e.g. Atlas of Living Australia, Feralscan). Others that have a broader scope, such as the NSW Landcare Gateway, do not include key features such as private group spaces or the ability for general users to upload photos and observation data (at least at the time the survey was conducted).

The high level of usage of mobile devices in the case study area makes it essential that any locally-developed tool is compatible with phones and tablets. This reflects the latest global trends around collaborative geospatial tools (Palomino et al., 2017). Even in the SW case study area, where landholders reported lower usage of mobile devices (possibly due to poor internet access or demographic factors), mobile access is likely to become more significant over time. However, the prevalence of PC and laptop usage in the SW case study area highlights the need to ensure that tools are not mobile-only (e.g. existing solely as apps for smartphones).

Designers of online tools also need to account for the prevalence of slow and unreliable internet access in rural areas. This may mean avoiding large complex graphics and simplifying mapping and photo functions to ensure users with slow internet can still benefit from the sharing of results and case studies (e.g. making photos viewable only after users select them). Text-based search options may be preferable to map-based searches in this region, based on internet speeds and the preferences expressed by the surveyed landholders. As links to social media and discussion forums were not rated highly, online tools could include these as extra features rather than core functions.

Apart from phone/tablet compatibility and fast access speeds, respondents associated user-friendliness with simple menu options. As such, online tools should provide limited menu options and clear descriptions. This reflects the recommendation of Mekonnen \& Gorsevski (2015) to employ easy-to-use features and may help to 
overcome barriers related to a lack of technological literacy among certain demographic groups identified in other studies (Carver et al., 2009; Haklay, 2013).

Internet usage in this study was lower in the SW area, which had poorer reported internet quality as well as a higher proportion of commercial farmers who had lived in rural areas all their lives. A limitation of this study is that the survey data on internet quality was recorded separately from interview data on land use and rural/urban origin and thus could not be analysed for correlations. Larger-scale regional surveys could enable statistical analysis of such correlations, but should be complemented by localscale participatory approaches to ensure that collaboration tools are adaptable to local conditions and preferences.

Surveyed landholders in both areas expressed a strong interest in a tool with differing levels of access, such as the use of private group spaces to share sensitive data. Data security was highly valued and would need to be ensured for contact details and any data that could be linked to an individual property. The design of a new collaborative tool for the region should allow for a select group (e.g. a Landcare group) to share sensitive data with one another, while only making general or non-sensitive data available to the broader public (e.g. generalized monitoring results from the Landcare group rather than results from each individual property).

Surveyed landholders indicated a willingness to pay a fee, though the value of the site would need to be demonstrated first, especially due to the number of free online collaboration tools available (Palomino et al., 2017). As much of the site's value depends on its use by landholders, one strategy may be to build up a critical mass of users before any fee is imposed. Another could be to employ the "freemium" approach taken by other tools, which provide free use of basic functions, but charge for increased 
functionality (Palomino et al., 2017). It is also important to note that tools that are "free" in the sense of having no fees may still require an investment of time to set up and that a lack of fees or charges does not necessarily mean that a tool is open-source (i.e. readily able to be customised to user needs).

A final implication of the case study relates to the framing of any online tool developed for the area. Two common approaches to framing online collaboration tools are participatory mapping (or PGIS) and citizen science. However, when asked about the functions that were most important to them, landholders in the case study areas rated mapping and the uploading of monitoring data below data security, the ability to set differentiated sharing settings and the need for a key term search. This indicates that landholders were less concerned with the types of data they would be sharing (e.g. spatial, monitoring data) than they were with how that data would be shared. To align with landholder priorities, data of all types would need to be stored in a secure manner that allows for differentiated access level and searching and navigation using key terms and simple menu options.

The case study results have implications for the development of online collaboration tools for landholders beyond the case study site. Developers of PGIS approaches in other locations have encountered differences between their expectations and those of potential users (Ramsey, 2009). One option to avoid placing limits on how such tools could be used is to refrain from using terms such as PGIS, citizen science or social media during the early design phase of such tools.

An adaptive approach to the development of online collaboration tools involves designing tools that can be used for key purposes such as mapping, reporting observations or linking to social media, but also ensuring that tools are flexible enough 
to cater for emergent uses arising from the changing needs and aspirations of users.

Such an approach requires designers to consider how to engage users in the redesign or "hacking" of collaborative tools (Haklay, 2013). This approach could also advance “adaptive co-management" (Berkes, 2007) by enabling local stakeholders to work together to adapt not only their land management strategies but also the ways in which they collaborate over time.

\section{Conclusion}

Online tools for landholder collaboration offer the potential to enhance communication and social connectivity, identify landscape-scale opportunities, share data and management practices, divide up tasks and integrate complementary functions in one place. However, such tools must meet the needs of local users and be adaptable to changing circumstances. Done well, the use of online tools could help to overcome barriers relating to changing landholder demographics and to enhance collaboration in line with the principles of adaptive co-management.

This study highlights how issues such as internet access, privacy, technological proficiency and differing objectives can influence the design of an online collaboration tool for land management by landholders. While surveyed landholders were interested in having access to mapping and data upload functions, they expressed stronger preferences for functions relating to data security, sharing settings and key term searches. As such, care should be taken when framing any new tool developed for the region exclusively as PGIS, citizen science, social media or other restrictive terms. A truly adaptive online tool for the case study region would incorporate mapping and data upload functions but would allow space for adaptation over time in line with changing landholder objectives around land management and collaboration strategies. 


\section{Acknowledgements}

The authors would like to thank the case study participants for their time and insights and also Ana Lambert Grossi and Katie Coleborn for their help with summarising and organising the literature reviewed in this article.

\section{Declaration of interest}

This research was funded through a grant from the Environmental Research Program of the New South Wales Environmental Trust (Grant Reference No. 2015/RD/0145). 


\section{References}

Al-Wadaey, A., Ziadat, F., 2014. A participatory GIS Approach to Indentify Critical Land Degradation Areas and Prioritize Soil Conservation for Mountainous Olive Groves (Case Study). Journal of Mountain Science 11, 782-791.

Ampt, P., Baumber, A., 2010. Building Cooperation and Collaboration in the Kangaroo Industry: Towards a role for landholders. Rural Industries Research and Development Corporation, Canberra, p. 138.

Ampt, P., Doornbos, S., 2011. Communities in Landscapes project: Benchmark Study of Innovators. Caring for Our Country Program, Australian Government, University of Sydney, p. 40.

Baumber, A., Cooney, R., Ampt, P., Gepp, K., 2009. Kangaroos in the rangelands: opportunities for landholder collaboration. The Rangeland Journal 31, 161-167. Baumber, A., Rammelt, C., Ampt, P., Merson, J., 2012. Bioenergy from Native Agroforestry: Planning for a Regional Industry in the NSW Central Tablelands. Rural Industries Research and Development Corporation, Canberra, p. 84

Berkes, F., 2007. Adaptive Co-Management and Complexity: Exploring the Many Faces of Co-Management, in: Armitage, D., Berkes, F., Doubleday, N. (Eds.), Adaptive Co-Management. UBC Press, Vancouver, pp. 19-37.

Bonney, R., Ballard, H., Jordan, R., McCallie, E., Phillips, T., Shirk, J., Wilderman, C.C., 2009. Public Participation in Scientific Research: Defining the Field and Assessing Its Potential for Informal Science Education - a CAISE Inquiry Group Report. Center for Advancement of Informal Science Education,, Washington, DC. 
Brown, G., Kytta, M., 2014. Key issues and research priorities for public participation GIS (PPGIS): A synthesis based on empirical research. Applied Geography 46, 122136.

Bureau of Meteorology, 2012. Climate Data Online: Climate Statistics for Condobolin Ag Research Station, Oberon (Springbank), Bathurst Agricultural Station, Lithgow (Birdwood St) \& Mudgee (George St). Bureau of Meteorology,.

Byrne, D., Pickard, A.J., 2016. Neogeography and the democratization of GIS: a metasynthesis of qualitative research. Information, Communication \& Society 19, 15051522.

Campbell, J.R., 2001. Participatory Rural Appraisal as Qualitative Research:

Distinguishing Methodological Issues from Participatory Claims. Human Organization 60, 380-389.

Carver, S., Evans, A., Kingston, R., Turton, I., 2001. Public Participation, GIS, and Cyberdemocracy: Evaluating on-Line Spatial Decision Support Systems. Environment and Planning B: Planning and Design 28, 907-921.

Carver, S., Watson, A., Waters, T., Matt, R., Gunderson, K., Davis, B., 2009.

Developing Computer-Based Participatory Approaches to Mapping Landscape Values for Landscape and Resource Management, in: Geertman, S., Stillwell, J. (Eds.), Planning Support Systems Best Practice and New Methods. Springer Science+Business Media, Netherlands, pp. 431-448.

Central West Catchment Management Authority, 2007. Central West Catchment Action Plan 2006-2016. Central West Catchment Management Authority, Dubbo, p. 95. 
Central West Independent Review Panel, 2007. Review of Land Use Planning in the

Central West: Report to the Minister for Planning. Central West Rural Lands Inquiry, Sydney, p. 22.

Chambers, R., 1994. The origins and practice of participatory rural appraisal. World Development 22, 953-969.

Cinnamon, J., Schuurman, N., 2013. Confronting the data-divide in a time of spatial turns and volunteered geographic information. GeoJournal 78, 657-674.

Compton, E., Beeton, R.J.S., 2012. An accidental outcome: Social capital and its implications for Landcare and the "status quo". Journal of Rural Studies 28, 149-160.

Cravens, A.E., 2014. Needs before tools: using technology in environmental conflict resolution. . Conflict Resolution Quarterly 32, 3-32.

Cravens, A.E., 2016. Negotiation and decision making with collaborative software: how MarineMap 'changed the game' in California's Marine Life Protected Act Initiative. Environmental management 57, 474-497.

Curtis, A., Ross, H., Marshall, G.R., Baldwin, C., Cavaye, J., Freeman, C., Carr, A., Syme, G.J., 2014. The great experiment with devolved NRM governance: lessons from community engagement in Australia and New Zealand since the 1980s. Australasian Journal of Environmental Management 21, 175-199.

FeralScan, 2017. Feralscan.org.au. Centre for Invasive Species Solutions.

Franzoni, C., Sauermann, H., 2014. Crowd science: The organization of scientific research in open collaborative projects. Research Policy 43, 1-20.

Goodchild, M., Li, L., 2012. Assuring the quality of volunteered geographic information. Spatial Statistics 1, 110-120. 
Goodchild, M.F., 2007. Citizens as sensors: the world of volunteered geography. GeoJournal 69, 211-221.

Haklay, M., 2013. Neogeography and the Delusion of Democratisation. Environment and Planning A 45, 55-69.

Holmes, J., 2006. Impulses towards a multifunctional transition in rural Australia: Gaps in the research agenda. Journal of Rural Studies 22, 142-160.

Jankowski, P., 2009. Towards participatory geographic information systems for community-based environmental decision making. Journal of Environmental Management 90, 1966-1971.

Karimi, A., Brown, G., 2017. Assessing multiple approaches for modelling land-use conflict potential from participatory mapping data. Land Use Policy 67, 253-267.

Lawrence, A., Paudel, K., Barnes, R., Malla, Y., 2007. Adaptive value of participatory biodiversity monitoring in community forestry. Environmental Conservation 33, 325334.

Lockwood, A.C.M., 2000. Landcare and Catchment Management in Australia: Lessons for State-Sponsored Community Participation. Society \& Natural Resources 13, 61-73. Marchand, F., Debruyne, L., Triste, L., Gerrard, C., Padel, S., Lauwers, L., 2014. Key characteristics for tool choice in indicator-based sustainability assessment at farm level. Ecology and Society 19, 46.

Meadows, J., Emtage, N., Herbohn, J., 2014. Engaging Australian small-scale lifestyle landowners in natural resource management programmes - Perceptions, past experiences and policy implications. Land Use Policy 36, 618-627. 
Meyer, W.S., Bryan, B.A., Summers, D.M., Lyle, G., Wells, S., McLean, J., Siebentritt, M., 2016. Regional engagement and spatial modelling for natural resource management planning. Sustainability Science 11, 733-747.

Narayanasamy, N., 2009. Participatory rural appraisal: Principles, methods and application. SAGE Publications Ltd., New Delhi.

Newman, G., Chandler, M., Clyde, M., McGreavy, B., Haklay, M., Ballard, H., Gray, S., Scarpino, R., Hauptfeld, R., Mellor, D., Gallo, J., 2017. Leveraging the power of place in citizen science for effective conservation decision making. Biological Conservation 208, 55-64.

Newman, G., Zimmerman, D., Crall, A., Laituri, M., Graham, J., Stapel, L., 2010. Userfriendly web mapping: lessons from a citizen science website. International Journal of Geographical Information Science 24, 1851-1869.

NSW Government, 2007. Land Use Mapping - New South Wales. Spatial Products and Services, NSW Government, Grafton, p. 34.

Palomino, J., Muellerklein, O.C., Kelly, M., 2017. A review of the emergent ecosystem of collaborative geospatial tools for addressing environmental challenges. Computers, Environment and Urban Systems 65, 79-92.

Ramsey, K., 2009. GIS, modeling, and politics: On the tensions of collaborative decision support. Journal of Environmental Management 90, 1972-1980.

Rickenbach, M., Schulte, L., Kittredge, D., Labich, W., Shinneman, D., 2011. Crossboundary cooperation: A mechanism for sustaining ecosystem services from private lands,. Journal of Soil and Water Conservation 66, 91-96. 
Robards, M., Silber, G., Adams, J., Arroyo, J., Lorenzini, D., Schwehr, K., Amos, J., 2016. Conservation science and policy applications of the marine vessel Automatic Identification System (AIS) - a review. Bulletin of Marine Science 92, 75-103.

Rotman, D., Preece, J., Hammock, J., Procita, K., Hansen, D., Parr, C., Lewis, D., Jacobs, D., 2012. Dynamic Changes in Motivation in Collaborative Citizen-Science Projects, ACM 2012 conference on Computer Supported Cooperative Work. Association for Computing Machinery, Seattle, Washington, USA - February 11 - 15, 2012 pp. $217-226$.

Tennent, R., Lockie, S., 2013. Vale Landcare: the rise and decline of community-based natural resource management in rural Australia. Journal of Environmental Planning and Management 56, 572-587.

The Atlas of Living Australia, 2017. The Atlas of Living Australia. The Atlas of Living Australia.

Turner, A.J., 2006. Introduction to Neogeography. O'Reilly, Sebastopol, CA.

Wang, X., Yu, Z., Cinderby, S., Forrester, J., 2008. Enhancing participation:

Experiences of participatory geographic information systems in Shanxi province, China. Applied Geography 28, 96-109.

Wyborn, C., Bixler, R.P., 2013. Collaboration and nested environmental governance:

Scale dependency, scale framing, and cross-scale interactions in collaborative conservation. Journal of Environmental Management 123, 58-67. 